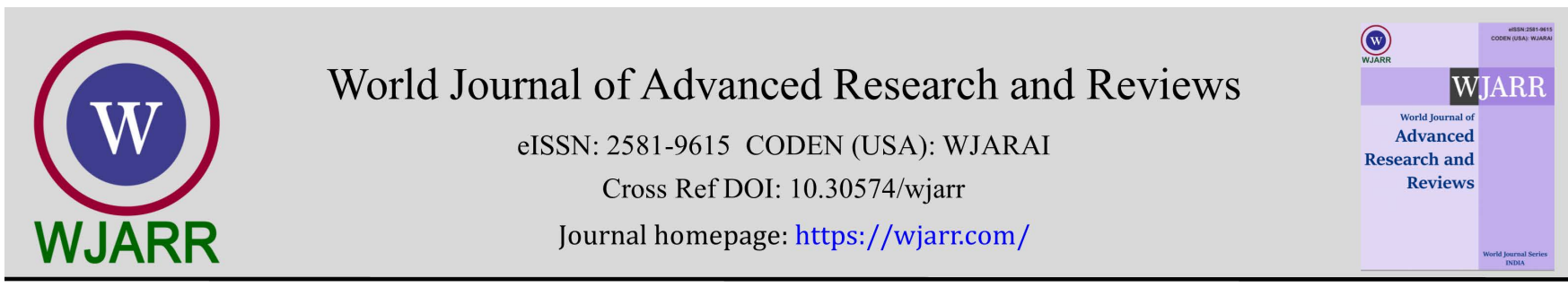

(RESEARCH ARTiClE)

\title{
The effects of rutin and quercetin on ECG parameters in 5-FU-induced cardiotoxicity rat model
}

\author{
Volkan Gelen ${ }^{1,}{ }^{*}$ Emin Şengül ${ }^{2}$ and Dursun Ali Çınar² \\ ${ }^{1}$ Department of Physiology, Veterinary Faculty, Kafkas University, Kars, Turkey, \\ 2 Department of Physiology, Veterinary Faculty, Ataturk University, Erzurum, Turkey.
}

World Journal of Advanced Research and Reviews, 2021, 09(03), 253-257

Publication history: Received on 10 February 2021; revised on 13 March 2021; accepted on 16 March 2021

Article DOI: https://doi.org/10.30574/wjarr.2021.9.3.0104

\begin{abstract}
5-fluorouracil (5-FU), a pyrimidine analogue anticarcinogenic agent, is widely used in the solid tumors treatment. Use of the 5-FU causes cardiotoxicity. Our aim in this study investigations effects of Quercetin and Rutin on ECG parameters in the 5-FU-induced cardiotoxicity in rats. In the present study used male rats. Rats were divided randomly to eight group. The control group was given intragastric corn oil for 14 days. The 5-FU group rats were given ig corn oil for 14 days and injected intraperitoneal the single dose of 5-FU(50 mg/kg) on the eleventh day. The Q50+5-FU and Q100+5FU groups were given ig $50 \mathrm{mg} / \mathrm{kg}$ and $100 \mathrm{mg} / \mathrm{kg} \mathrm{Q}$ for 14 days, respectively and these groups were injected single dose of 5 -FU(50 mg/kg) on the 11 th days of Q application. The group Q100 was Q(100 mg/kg-ig) for 14 days. The Rutin50+5-FU and Rutin100+5-FU groups were injected ig $50 \mathrm{mg} / \mathrm{kg}$ and $100 \mathrm{mg} / \mathrm{kg}$ of the Rutin for 14 days, respectively. These groups were injected single dose of $5-\mathrm{FU}(50 \mathrm{mg} / \mathrm{kg})$ in the 11 th days of Rutin application. The Rutin 100 group was given Rutin(100 mg/kg-ig) for 14 days. In the end of experimental application recorded to ECGs of the rats. 5-FU administration rats were observed that it was caused sinus tachycardia and ST elevation. Also, in the 5-FU group QRS segment was shorter and the duration and amplitude of the $\mathrm{P}$ was different from other groups. In both doses of $Q$ and Rutin were prevented these changes and our findings were seen the consistent with the literature.
\end{abstract}

Keywords: 5-FU; ECG; Quercetin; Rutin; Rat

\section{Introduction}

5-fluorouracil (5-FU) is an agent with fluoropyrimidine antimetabolite, which is widely used in pancreatic and skin cancer treatment (1). Gastrointestinal and hematologic toxicities are one of the most common side effects of the 5-FU (2). Cardiotoxicity, well recognized for other antineoplastic agents, is major complication of 5-FU and the cardiotoxicity resulting from use of 5-FU is characterized by angina, pulmonary edema, congestive heart failure, myocardial infarction, ventricular arrhythmias, myocardial ischemia and sudden death (3-6). The recent studies have reported that has increased cardiotoxicity cases due to 5-FU (7). The 5-FU's itself or its metabolites are toxic for myocytes (8) and Fluorouracil uptake into the myocardium has been demonstrated $(9,10)$. The animal studies has showed positive chronotropic and inotropic effects of 5-FU (11) and the heart rates have founded to elevate during 5-FU administration (12). It has reported that in the 5-FU treatment occurs acute global left ventricular dysfunction. In the first cycle of administration of 5-FU infusions prone to become the cardiotoxicity the patient (13) and the symptoms is initiation nearly $12 \mathrm{~h}$ following of the infusion (14). To prevent or treat the toxic effects of anticancer agents as 5-FU are commonly used different antioxidant compounds. Quercetin (Q) and Rutin, are natural flavonoids, have strong antioxidant effects, which available in many fruits and vegetables (15-22). The aim of the present study, investigations effects of Q and Rutin on ECG parameters in the 5-FU-induced cardiotoxicity in rats.

\footnotetext{
* Corresponding author: Volkan GELEN

Department of Physiology, Veterinary Faculty, Kafkas University, Kars, Turkey.

Copyright $(2021$ Author(s) retain the copyright of this article. This article is published under the terms of the Creative Commons Attribution Liscense 4.0.
} 


\section{Material and methods}

In the study, 80 piece adult male Sprague Dawley rats was used, whose weights were 220-250 g. All the animals were housed under standard environment conditions and were allowed access to a standard diet and ad libitum drinking water. The rats were randomly divided into eight groups and there was 10 rats in each group. The control group was given only intragastric (i.g.) solvent (corn oil) for 14 days. The 5-FU group was given i.g. corn oil for 14 days and singledose intraperitoneal (i.p.) $5-\mathrm{FU}(50 \mathrm{mg} / \mathrm{kg})$ was injected on the 11 th day of the study. The Q50+5-FU and Q100+5-FU groups were administered i.g. the 50 and $100 \mathrm{mg} / \mathrm{kg}$ doses of Q dissolved in corn oil for 14 days and injected single dose (50 mg / kg, i.p.) of 5-FU on the 11th day. The Q100 group was given Q (100 mg/kg, i.g.) for 14 days. The Rutin50+5-FU and Rutin100+5-FU groups were given i.g. doses of 50 and $100 \mathrm{mg} / \mathrm{kg}$ of Rutin dissolved in corn oil for 14 days, respectively and single dose (50 mg / kg, i.p.) of 5-FU was administered on the 11 th day. The Rutin 100 group was given Rutin (100 mg/kg, i.g.) for 14 days. On the 15th day of the experiment, the ECG of the rats in all groups were recorded with cardiyofax 6851 (Nihon Kohden Cardiofax C (ECG-2150), Tokyo, Japan).

\subsection{Electrocardiographic measurements}

In all derivations were used crocodile electrodes. Electrodes were placed on the elbow joints in the front skirts, just above the knee joints in the back skirts and bipolar extremity derivations (I, II and III) and increased unipolar extremity derivations (aVR, aVL and aVF) were recorded. After 72 hours from 5-FU treatment, ECG tracings (lead II) were recorded by means of an electrocardiograph connected to crocodile electrodes in rats. Nihon Kohden Cardiofax C (ECG-2150) connected to an acquisition data system was used to record and monitor ECG tracings. Analysis of ECG tracings was measured the duration of the P, P-Q, QRS, Q-T and T intervals, QRS voltage and heart rate. These ECG parameters are considered to be predictive of cardiac damages induced by 5-FU treatment. Electrocardiograms were taken with crocodile electrodes. Electrodes were placed the connecting sections to the body of the front and back legs. The areas where the electrodes were placed were thoroughly fixed with electrode gel. ECGs were taken in a quiet environment after the rats are expected to calm down. Bipolar extremity derivations were recorded six derivations as the right anterior and left anterior leg I. derivation, the right anterior and left posterior leg II. Derivation, the left anterior and left posterior leg III. Derivation and increased unipolar extremity (aVR, AVL, AVF) derivations.

\subsection{Statistical analysis}

All data were statistically evaluated by one-way ANOVA using SPSS 20.00, followed by Tukey test. The data were expressed as mean \pm SD. $\mathrm{p}<0.05$ was considered statistically significant.

\section{Results}

In the ECG parameters recorded from the rats in the experimental groups, the mean heart rates of the rats in the control group was determined as $252 \pm 14$. The number of heart beat in the 5 -FU group was $314 \pm 17$ and 5 -FU caused sinus tachycardia. Also, in the 5-FU group was observed ST elevation. It was determined that both doses of Q and Rutin were prevented the sinus tachycardia caused by $5-\mathrm{FU}(\mathrm{P}<0.05$, Fig and Table). The heart rate numbers of rats in $\mathrm{Q} 100$ and Rutin 100 groups did not change $(\mathrm{P}>0.05$, Fig and Tab). The duration and amplitude of the $\mathrm{P}$ wave in the ECG trays obtained from the groups did not different among the groups, But there was a difference in the 5 -FU group (P<0.05, Fig). The time of interval and QRS segment was shorter in the 5-FU group. 
Table 1 The effect of $Q$ and Rutin on 5-FU-induced alterations in ECG.

\begin{tabular}{|c|c|c|c|c|c|c|c|c|}
\hline Parameters & Control & 5-FU & $\begin{array}{l}\text { Rutin50+5- } \\
\text { FU }\end{array}$ & $\begin{array}{l}\text { Rutin100+5- } \\
\text { FU }\end{array}$ & $\begin{array}{l}\text { Q50+5- } \\
\text { FU }\end{array}$ & $\begin{array}{l}\text { Q100+5- } \\
\text { FU }\end{array}$ & Rutin100 & Q100 \\
\hline $\mathrm{P}(\mathrm{s})$ & $\begin{array}{l}0.02 \pm \\
0,00\end{array}$ & $\begin{array}{l}0.02 \pm \\
0,00\end{array}$ & $0.02 \pm 0,00$ & $0.02 \pm 0,00$ & $\begin{array}{l}0.02 \pm \\
0,00\end{array}$ & $\begin{array}{l}0.02 \pm \\
0,00\end{array}$ & $\begin{array}{l}0.02 \pm \\
0,00\end{array}$ & $0.02 \pm 0,00$ \\
\hline $\mathrm{P}(\mathrm{mV})$ & $\begin{array}{l}0.1 \pm \\
0,00\end{array}$ & $0.1 \pm 0,00$ & $0.1 \pm 0,00$ & $0.1 \pm 0,00$ & $\begin{array}{l}0.1 \pm \\
0,00\end{array}$ & $0.1 \pm 0,00$ & $0.1 \pm 0,00$ & $0.1 \pm 0,00$ \\
\hline$P-Q(s)$ & $\begin{array}{l}0.04 \pm \\
0,00\end{array}$ & $\begin{array}{l}0.03 \pm \\
0,00^{*}\end{array}$ & $0.04 \pm 0,00$ & $0.04 \pm 0,00$ & $\begin{array}{l}0.04 \pm \\
0,00\end{array}$ & $\begin{array}{l}0.04 \pm \\
0,00\end{array}$ & $\begin{array}{l}0.04 \pm \\
0,00\end{array}$ & $\begin{array}{l}0.04 \pm \\
0,00\end{array}$ \\
\hline QRS (s) & $\begin{array}{l}0.06 \pm \\
0,00\end{array}$ & $\begin{array}{l}0.05 \pm \\
0,00^{*}\end{array}$ & $0.06 \pm 0,00$ & $0.06 \pm 0,00$ & $\begin{array}{l}0.06 \pm \\
0,00\end{array}$ & $\begin{array}{l}0.06 \pm \\
0,00\end{array}$ & $\begin{array}{l}0.06 \pm \\
0,00\end{array}$ & $\begin{array}{l}0.06 \pm \\
0,00\end{array}$ \\
\hline QRS (mV) & $\begin{array}{l}0.5 \pm \\
0,00\end{array}$ & $\begin{array}{l}0.2 \pm \\
0,00^{* *}\end{array}$ & $0.8 \pm 0,00^{* *}$ & $0.7 \pm 0,00^{* *}$ & $\begin{array}{l}0.6 \pm \\
0,00^{*}\end{array}$ & $\begin{array}{l}0.6 \pm \\
0,00^{*}\end{array}$ & $\begin{array}{l}0.8 \pm \\
0,00^{* *}\end{array}$ & $\begin{array}{l}0.6 \pm \\
0,00^{*}\end{array}$ \\
\hline Q-T (s) & $\begin{array}{l}0.08 \pm \\
0,00\end{array}$ & $\begin{array}{l}0.07 \pm \\
0,00\end{array}$ & $0.076 \pm 0,00$ & $0.076 \pm 0,00$ & $\begin{array}{l}0.08 \pm \\
0,00\end{array}$ & $\begin{array}{l}0.08 \pm \\
0,00\end{array}$ & $\begin{array}{l}0.08 \pm \\
0,00\end{array}$ & $\begin{array}{l}0.077 \pm \\
0,00\end{array}$ \\
\hline $\mathrm{T}(\mathrm{s})$ & $\begin{array}{l}0.03 \pm \\
0,00\end{array}$ & $\begin{array}{l}0.03 \pm \\
0,00\end{array}$ & $0.03 \pm 0,00$ & $0.03 \pm 0,00$ & $\begin{array}{l}0.03 \pm \\
0,00\end{array}$ & $\begin{array}{l}0.03 \pm \\
0,00\end{array}$ & $\begin{array}{l}0.03 \pm \\
0,00\end{array}$ & $\begin{array}{l}0.03 \pm \\
0,00\end{array}$ \\
\hline $\mathrm{T}(\mathrm{mV})$ & $\begin{array}{l}0.1 \pm \\
0,00\end{array}$ & $0.1 \pm 0,00$ & $0.1 \pm 0,00$ & $0.1 \pm 0,00$ & $\begin{array}{l}0.1 \pm \\
0,00\end{array}$ & $0.1 \pm 0,00$ & $0.1 \pm 0,00$ & $0.1 \pm 0,00$ \\
\hline $\begin{array}{l}\text { Heart rate } \\
\text { (beats/min) }\end{array}$ & $252 \pm 14$ & $324 \pm 17^{* *}$ & $280 \pm 15$ & $235 \pm 23$ & $280 \pm 15$ & $269 \pm 16$ & $240 \pm 17$ & $240 \pm 18$ \\
\hline $\begin{array}{l}\text { Electrical } \\
\text { axis } \\
\text { (degrees) }\end{array}$ & $48 \pm 10$ & $45 \pm 9$ & $43 \pm 7$ & $42 \pm 5$ & $43 \pm 8$ & $45 \pm 10$ & $46 \pm 8$ & $44 \pm 9$ \\
\hline
\end{tabular}

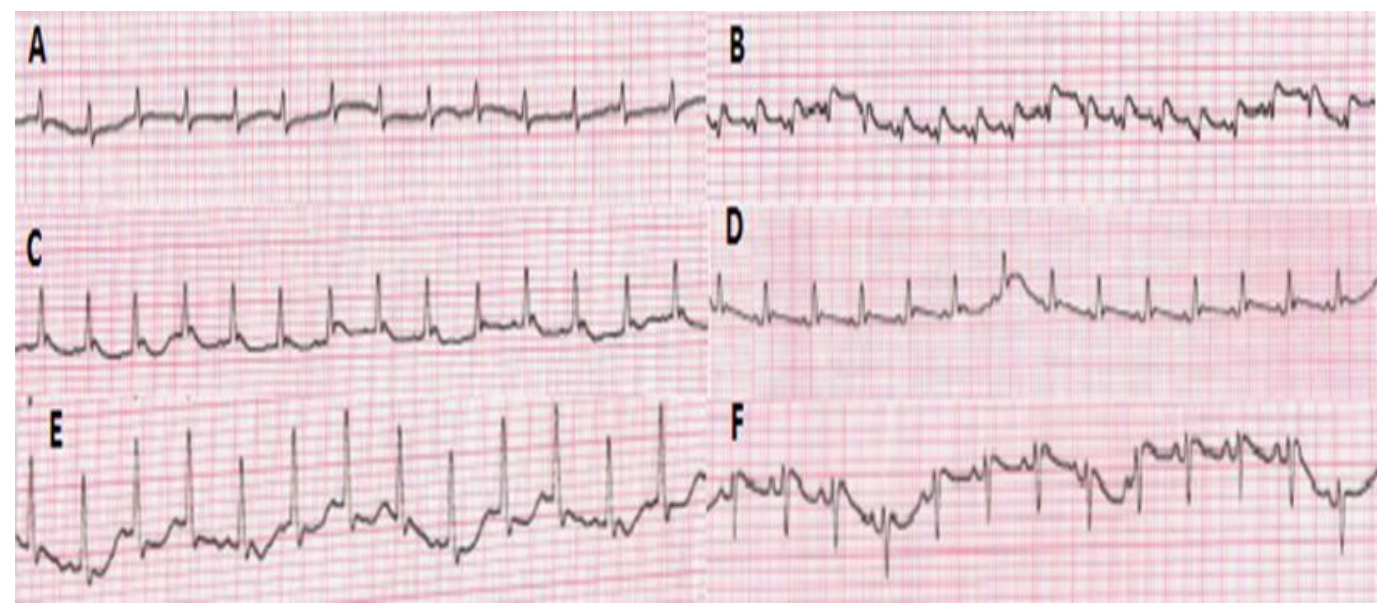

Figure 1 EKG traces of the Control (A), 5-FU (B), Q50+5-FU (C), Q100+5-FU (D), RUTIN50+5-FU (E), RUTİN100+5-FU (F) $(n=10, p<0.05)$.

\section{Discussion}

5-flourouracil (5-FU) has been commonly used as chemotherapeutic in the treatment of gastrointestinal malignancies for years. Unfortunately, as well as its beneficial antitumor effects, 5-FU also have the some toxicities which cardiotoxicity is one of these toxicities (23). The some flavonoids are widely used in researches for to prevent or treat the possible side effects of anticancer agents (24-28). The $Q$ and Rutin compounds used for this purpose is found in the 
structure of many fruits and plants $(18,19)$. In this study, in the 5-FU-induced cardiotoxicity model in rats was determined the possible protective effects of Q and Rutin. ECG is a frequently used parameter in the evaluation of cardiac function. One of the methods currently used for the early detection of anticancerogens-induced cardiotoxicity is ECG measurement. Cardiac side effects of 5-FU, which an anticancer agent, are rhythm abnormalities, supraventricular and ventricular dysrhythmias (29) and acute myocardial infarction was also reported in the literature (30). It has reported that in nearly $88 \%$ of patients receiving infusions of 5-FU have determined the troponin release, asymptomatic ECG changes and in approximate 68\%, ST-segment deviation and QT-prolongation has observed (11, 14 ). Also, the studies has showed that the heart rates have elevated with positive chronotropic and inotropic effects of 5-FU (12).

\section{Conclusion}

In our study, 5-FU administration rats were observed that it was caused sinus tachycardia and ST elevation. Also, in the 5-FU group QRS segment was shorter and the duration and amplitude of the P was different from other groups. 5-FUinduced ECG changes in rats were determined for the first time in our study. In both doses of Q and Rutin were prevented these changes.

\section{Compliance with ethical standards}

\section{Acknowledgments}

We would like to thank Atatürk University Veterinary Faculty Physiology Laboratory.

\section{Disclosure of conflict of interest}

The authors declare that there are no conflicts of interest.

\section{Statement of ethical approval}

Animal experiments were performed in accordance with the national guidelines for the use and care of laboratory animals and were approved by the Local Ethics Committee of Ataturk University for Animal Experiments (Protocol no: 2017/72).

\section{References}

[1] Rossi S, editor. Australian medicines handbook. 2013 ed. Adelaide: The Australian Medicines Handbook Unit Trutinst; 2013 ISBN 978-0-9805790-9-3.

[2] Meta-Analysis Group In Cancer, Lévy E, Piedbois P, Buyse M, Pignon JP, Rougier P, Ryan L, Hansen R, Zee B, Weinerman B, Pater J, Leichman C, Macdonald J, Benedetti J, Lokich J, Fryer J, Brufman G, Isacson R, Laplanche A, Quinaux E, Thirion P. Toxicity of fluorouracil in patients with advanced colorectal cancer: Effect of administration schedule and prognostic factors-Meta-Analysis Group in Cancer. J Clin Oncol 16:3537-3541, 1998.

[3] Sengul E, Gelen V, Gedikli S. Cardıoprotectıve Actıvitıes Of Quercetın And Rutın In Sprague Dawley Rats Treated With 5-Fluorouracil. Journal Of Animal \& Plant Sciences. Apr 2021; 31(2): P423-431.

[4] Polk A, Vistisen K, Vaage-Nilsen M, Nielsen DL. A systematic review of the pathophysiology of 5-fluorouracilinduced cardiotoxicity. BMC Pharmacol Toxicol. 2014; 15: 47.

[5] Sorrentino MF, Kim J, Foderaro AE, Truesdell AG. 5-fluorouracil induced cardiotoxicity: review of the literature. Cardiol J 2012; 19: 453-8.

[6] Tsavaris N, Kosmas C, Vadiaka M, Efremidis M, Zinelis A, Beldecos D, et al. Cardiotoxicity following different doses and schedules of 5-fluorouracil administration for malignancy- a survey of 427 patients. Med Sci Monit. 2002; 8(6): PI51-7.

[7] Jensen SA, Sørensen JB. 5-Fluorouracil-based therapy induces endovascular injury having potential significance to development of clinically overt cardiotoxicity. Cancer Chemother Pharmacol. 2012; 69(1): 57-64.

[8] Ensley J, Kish J, Tapazoglou E, Patel B, Kloner R, Wynne J, et al. 5-fluorouracil infusions associated with an ischemic cardiotoxicity syndrome. Proc Am Soc Clitf Oncol. 1986; 5: 142.

[9] Mizuno Y, Hokamura Y, Kimura T, Kimura Y, Kaikita K, Yasue H. A case of 5-fluorouracil cardiotoxicity simulating acute myocardial infarction. Jpn Circ J. 1995; 59(5): 303-7. 
[10] Liss RH, Chadwick M. Correlation of 5-fluorouracil (NSC-19893) distribution in rodents with toxicity and chemotherapy in man. Cancer Chemother Rep. 1974; 58: 777-86.

[11] De Forni M, Malet-Martino M, Jaillais P et al. Cardiotoxicity of high-dose continuous infusion florouracil: A prospective clinical study. J Clin Oncol. 1992; 10: 1795-1801.

[12] Rezkalla S, Kloner RA, Ensley J, et al. Continuous ambulatory ECG monitoring during fluorouracil therapy: a prospective study. J Clin Oncol. 1989; 7: 509-14.

[13] Robben NC, Pippas AW, Moore JO. The syndrome of 5-fluorouracil cardiotoxicity: an elusive cardiopathy. Cancer. 1993; 71: 493-509.

[14] Becker K, Erckenbrecht J, Haussinger D, Frieling T. Cardiotoxicity of the antiproliferative compound fluorouracil. Abstract. Drugs. 1999; 57: 475-484.

[15] Gelen V, Şengül E, Gedikli S, Atila G, Uslu H, Makav M. The protective effect of Rutin and quercetin on 5-FUinduced hepatotoxicity in rats. APJTB. 2017; 7(7): 930-934.

[16] Gelen V, Şengül E, Yildirim S, Çelebi F, Çinar DA. Effects of rutin on bladder contractility and histopathology in cyclophosphamide-induced hemorrhagic cystitis in rats. Ataturk University J Vet Sci. 2018; 13: 337-346.

[17] Gedikli S, E Sengul. The Effects Of Quercetin On Cyclophosphamide Induced Hepatotoxicity In The Rats. Dicle Medical J. 2019; 46(1): 41-50.

[18] Gibellini L, Pinti M, Nasi M, Montagna JP, De Biasi S, Roat E, Bertoncelli L, Cooper EL, Cossarizza A. Quercetin and cancer chemoprevention. Evid Based Complement Alternat Med. 2011; 591356.

[19] Manach C, Morand C, Demigné C, Texier O, Régérat F, Rémésy C. Bioavailability of rutin and quercetin in rats. FEBS Lett. 1997; 1: 12-6.

[20] Gelen V, Sengul E, Yildirim S, Atila G. The protective effects of naringin against 5-fluorouracil-induced hepatotoxicity and nephrotoxicity in rats. Iran J Basic Med Sci. 2018; 21: 404-410

[21] Kara A, Gedikli S, Sengul E, Gelen V, Ozkanlar S. Oxidative stress and autophagy, 1st edn. InTechOpen, Free Radicals and Diseases, London, 2016; 69-86

[22] Karamese M, Guvendi B, Karamese S A, Cinar I, Can S, Erol HS, Aydin H, Gelen Vand Karakus E. The protective effects of epigallocatechin gallate on lipo-polysaccharide-induced hepatotoxicity: an in vitro study on Hep3B cells. IranianJournal of Basic Medical Sciences 2016; 19: 483-489

[23] Kosmas C, Kallistratos M, Kopterides P, et al. Cardiotoxicity of fluoropyrimidines in different schedules of administration: A prospective study. J Cancer Res Clin Oncol. 2008; 134: 75-82.

[24] Razavi-Azarkhiavi K, Iranshahy M, Sahebkar A, Shirani K, Karimi G. The Protective Role of Phenolic Compounds Against Doxorubicin-induced Cardiotoxicity: A Comprehensive Review. Nutr Cancer. 2016 Aug-Sep; 68(6): 892917.

[25] Şengül E, Gelen V, Gedikli S, Özkanlar S, Gür C, Çelebi F, Çınar A. The protective effect of quercetin on cyclophosphamide-induced lung toxicity in rats. Biomed Pharmacother. 2017; 92: 03-307.

[26] Gelen V, Şengül E, Gedikli S, Gür C, Özkanlar S. Therapeutic effect of quercetin on renal function and tissue damage in the obesity induced rats. Biomed Pharmacother. 2017; 89: 524-528.

[27] Gelen V, E Sengul. Hematoprotective effect of naringin on 5-fu toxicity in rats. Chem. Res. J. 2018; 3(1): 127-130.

[28] Gelen V, E Sengul. Antioxidant, anti-inflammatory and antiapoptotic effects of Naringin on cardiac damage induced by cisplatin. Indian J. Tradit. Know. 2020; 19(2): 459-465.

[29] Oztop I, Gencer M, Okan T, et al. Evaluation of cardiotoxicity of a combined bolus plus infusional 5fluorouracil/folinic acid treatment by echocardiography, plasma troponin I level, QT interval and dispersion in patients with gastrointestinal system cancers. Jpn J Clin Oncol. 2004; 34(5): 262-268.

[30] Canale ML, Camerini A, Stroppa S, et al. A case of acute myocardial infarction during 5-fluorouracil infusion. J Cardiovasc Med. 2006; 7(11): 835-837. 